\title{
COMERCIO JUSTO Y RELEVO GENERACIONAL: LA EXPERIENCIA COLOMBIANA DE LA ASOCIACIÓN DE JÓVENES AGRICULTORES DEL VALLE.
}

\author{
FAIR COMMERCE AND GENERATIONAL CHANGE: THE COLOMBIAN \\ EXPERIENCE OF THE YOUNG FARMERS' ASSOCIATION FROM VALLE.
}

Recibido: febrero de 2013 - Revisado: agosto de 2013 - Aceptado: 30 de octubre de 2013

Por: Marco Coscione. ${ }^{1}$

\section{RESUMEN.}

En este artículo se presentan los resultados de investigación en torno a experiencias concretas y exitosas de relevo generacional que buscan mantener viva la cultura campesina a pesar de la invasión del pensamiento urbano en el Departamento del Valle del Cauca, en donde, tanto la cooperación público-privada, como las relaciones internacionales de comercio justo han influido en la generación de un mayor nivel de sostenibilidad económica, social e inter-generacional.

\section{PALABRAS CLAVE.}

Cultura campesina, vida digna, territorio, comercio justo.

\section{ABSTRACT.}

This article presents the results of research into concrete and successful generational experiences seeking to keep the peasant culture alive despite the invasion of the urban thought in the State of Valle del Cauca. In it, both public and private cooperation and international relations of fair trade have influenced the generation of a higher level of economic, social, and intergenerational sustainability.

\section{KEY WORDS AND EXPRESSIONS.}

Rural culture; Decent life; Territory; and Fair commerce.

\footnotetext{
${ }^{1}$ Licenciado en Ciencias Internacionales y Diplomáticas por la Universidad de Génova, Diplomado sobre "E1 Futuro de la Unión Europea y sus relaciones con América Latina. Hacia Viena 2006" (Universidad de Chile) y el Máster Oficial en "América Latina Contemporánea y sus relaciones con la UE: una cooperación estratégica" (Universidad de Alcalá e Instituto Universitario de Investigación Ortega y Gasset, Madrid). Tiene varias experiencias de estudio, trabajo y voluntariado en Europa (Italia, Alemania y España) y en América Latina (Cuba, Chile, Perú, El Salvador, Rep. Dominicana), Actualmente labora en República Dominicana. marco.coscione@gmail.com
} 


\section{Introducción.}

¿Cómo hacer atractivo el campo para los jóvenes?. Es un problema real que afecta a muchos países en el mundo, sobre todos aquellos países del Sur donde la población rural aún es relativamente fuerte en términos numéricos. Para el movimiento por un comercio justo y solidario el relevo generacional y la apuesta por nuevos liderazgos comunitarios han constituido siempre un gran desafío, más aún en la sociedad actual donde ser campesino o trabajar la tierra es sinónimo de pobreza, mientras que vivir en la ciudad es sinónimo modernidad, progreso y riqueza.

Desde el recrudecimiento de los problemas ambientales en las últimas décadas, se suelen escuchar declaraciones como "¡Hay que salvar el planeta!” o “¡Hay que dejarle un mejor planeta a nuestros hijos!", pero se nos olvida literalmente que el planeta Tierra se salvará de todas formas; ha resistido y ha vivido cambios climáticos y geológicos devastadores para sus habitantes animales durante milenios. Hoy, quien no se salvará será nuestra civilización, a menos que empecemos de verdad un cambio radical. Este cambio ya no depende de un enfoque dirigido a conservar "un planeta mejor" sino, más bien, de la construcción colectiva de una nueva generación; por tanto, habría que dejarle mejores hijos al planeta y no al revés.

Dejarles mejores hijos al planeta significa repensar completamente el rol del ser humano en nuestra civilización y reconstruir desde sus cimientos la relación entre los seres humanos, los animales y la naturaleza. "Mi papá me ha enseñado que el campo hay que quererlo", relata uno de los integrantes de la Asociación de Jóvenes Agricultores del Valle (Asojav), la organización de la cual hablaremos en este breve artículo. "Somos del campo y hay que quedar en el campo, y a los hijos hay que enseñarles lo mismo [...] somos campesinos arraigados [...] el futuro está en el campo, el hambre está en la ciudad, en el campo está la vida buena $\|^{2}$. Palabras llenas de orgullo y esperanza, pero que nos ponen de frente a un problema muy serio para las actividades rurales: el envejecimiento, los procesos de descampesinización y el necesario relevo generacional.

Dentro de las organizaciones de pequeños productores de comercio justo este debate está muy vivo; los productores entienden la importancia y urgencia de apostar por el relevo, pero a veces las condiciones estructurales del mundo rural y las "seducciones" del mundo urbano no garantizan que las ideas correctas lleguen de verdad a concretarse. En este artículo presentaremos la experiencia de Asojav, desde su conformación y sus relaciones con el comercio justo internacional. Este movimiento socio-económico internacional, hoy día, representa sin duda su mejor aliado para la gestión colectiva de un desarrollo rural y comunitario sostenible intergeneracionalmente.

\section{Metodologia.}

Para el desarrollo de este trabajo no se retomará tanto la historia del Comercio Justo (en adelante CJ) o sus actuales desafios, sino más bien se subrayarán la importancia del enfoque multidimensional o multisectorial que se implementa a través de relaciones comerciales justas y solidarias en este caso específico en experiencias concretas de CJ en Jóvenes Agricultores del Valle del Cauca. 


\section{Resultados.}

Progreso Network y el Concurso Relevo Generacional.

En septiembre de 2013, la Coordinadora Latinoamericana y del Caribe de Pequeños Productores de Comercio Justo (CLAC), la fundación holandesa Progreso, la ONG belga Trias y la Universidad Earth de Costa Rica lanzaron, a través de la plataforma "Progreso Network", el "Concurso Relevo Generacional". El objetivo fue llamar a las organizaciones de pequeños productores a que compartieran sus experiencias y trabajos relacionados con el desafio del relevo generacional en el campo, para finalmente escoger la mejor experiencia, a la cual se entregaría un premio de 3,000 dólares para seguir apoyando las buenas prácticas en ese ámbito. Al llamado respondieron varias organizaciones de la región, entre las cuales, tres de Nicaragua (la Unión de Cooperativas Agropecuarias y de Servicios "Soppexcca", la Asociación Pueblos en Acción Comunitaria "Apac" y la Unión de Cooperativas Agropecuarias "Augusto César Sandino" San Ramón), tres de Colombia (la Asociación de Jóvenes Agricultores del Valle "Asojav", la Asociación de productores Agroecológicos Indígenas y campesinos de la Sierra Nevada de Santa Marta y Serranía del Perijá "Asoanei” y la Asociación de Productores Indígenas Seynekun), cuatro de Perú (la Central de Servicios Cafetaleros del Nor Oriente "Cecanor", la Asociación de Pequeños Productores de Banano Orgánico "Appbosa" de Samán y Anexos, la Asociación de Productores Ecológicos "Aproeco" y la Cooperativa Agraria Cafetalera Café y Cacao Rio Negro Ltda.) y una de Honduras (Café Orgánico Marcala S.A. de C.V. "Comsa").

Entre estas organizaciones, las entidades convocantes escogieron a la Asociación de Jóvenes Agricultores del Valle (Tuluá, Valle del Cauca, Colombia) como ganadora por la mejor experiencia de relevo generacional.

El programa "Jóvenes Agricultores del Valle del Cauca”.

"En 1999, participamos en la convocatoria del programa Jóvenes Agricultores del Valle del Cauca", recuerda don Jorge Salinas ${ }^{4}$, actual presidente de Asojav, técnico en administración de empresas agropecuarias y, además, estudiante de ingeniería agronómica. "El objetivo concreto del programa era comprar varias fincas de agricultores mayores en dificultades económicas y revenderlas, a crédito, a jóvenes motivados y con voluntad de mantenerse ligados al campo y a la producción cafetera. Con intereses muy bajos y un plazo de 12 años, los jóvenes podiamos cancelar el valor del terreno adquirido". En esos años, entre 1999 y 2003 , los créditos para la compra del terreno oscilaban entre 8 y 15 millones de pesos.

El Programa “Jóvenes Agricultores del Valle del Cauca" surge en 1997 como iniciativa del Comité Departamental de Cafeteros (en asociación con la Cooperativa de Centrales Agrarias -Cencoa- del Valle del Cauca y, también, con el apoyo financiero de la Fundación para el Análisis y los Estudios Sociales -FAES- y de la cooperación española) ${ }^{5}$ para enfrentar el envejecimiento de los campesinos en las zonas rurales y apoyar la caficultura local también a través de capacitaciones y nuevos procesos de tecnificación. La necesidad de relevo generacional en el sector cafetero es evidente. Como recordaba, en marzo de 2012, el aquel entonces viceministro de agricultura, Ricardo Sánchez López, "mientras en Vietnam los cultivadores de café no llegan en promedio a los 30 años, en Colombia superan los 50 [...] el campo se nos está envejeciendo y hay que apostarle a un relevo generacional». ${ }^{6}$ 
A través de este programa, el Comité quería responder al abandono del campo por parte de los jóvenes, a causa de las escasas posibilidades para mantenerse ligados a la agricultura de manera sostenible, $\mathrm{y}$ "al no contar con una parcela propia para cultivar, lo cual coadyuvaba a la inserción de muchos de ellos en los grupos armados al margen de la ley" ${ }^{7}$. De hecho, el programa está incluido en "Banco de Buenas Prácticas para Superar el Conflicto", articulado por el Programa de Naciones Unidas para el Desarrollo (PNUD) en Colombia. Además, la Federación Nacional de Cafeteros presentó la experiencia al Banco Interamericano de Desarrollo (BID) con la idea de ampliar el modelo a escala nacional. "Pero al parecer no tuvo tanto éxito como en nuestro departamento", sentencia Jorge.

"Jóvenes Agricultores" se ejecutó en varios municipios del departamento del Valle. De hecho, los asociados de Asojav provienen de 15 diferentes municipios de los 42 que conforman el departamento: Ansermanuevo, Argelia, Buga, Caicedonia, Dagua, El Águila, El Cairo, Jamundi, La Cumbre, Obando, Sevilla, Trujillo, Tuluá, Versalles, Yotoco. Los objetivos específicos del programa fueron, entre otros:

"Promover el relevo generacional en las zonas rurales cafeteras del departamento, evitando la migración hacia centros urbanos, la vinculación a grupos armados y la participación en actividades ilícitas, dada las condiciones históricas de vulnerabilidad de los campesinos y la dinámica del conflicto armado.

Facilitar el acceso y uso a los jóvenes rurales de factores de producción como tierra y capital de trabajo, con el fin de mejorar sus condiciones de vida.

Convertir unidades agrícolas poco productivas en altamente productivas, mediante la adecuada implementación de las diferentes ofertas tecnológicas, protegiendo los recursos naturales mediante un proceso de intervención técnico y administrativo.

Incentivar la mano de obra familiar como factor productivo importante en el desarrollo de las diferentes actividades productivas.

Lograr el desarrollo individual, familiar y grupal de los beneficiarios del programa a través de procesos de capacitación y formación, que permitan impactar positivamente a la comunidad de la cual hacen parte.

Promover esquemas asociativos entre los beneficiaros de manera que realicen labores de cultivo, manejo de poscosecha y comercialización de los productos obtenidos en sus fincas». ${ }^{8}$ 


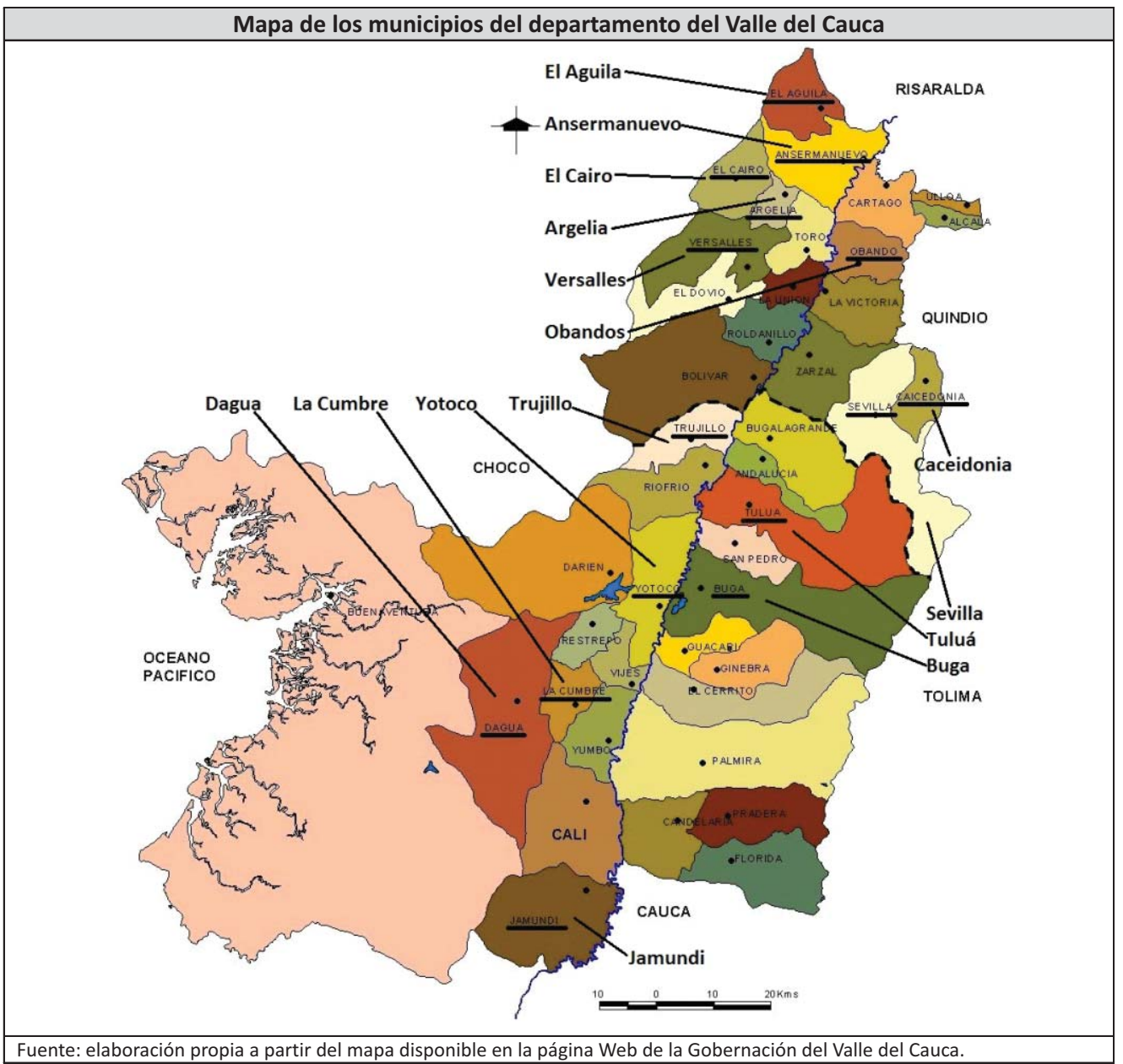

Para lograr dichos objetivos, el programa se desarrollaba en tres etapas fundamentales: la primera, "de conformación", duraba aproximadamente un semestre. Durante esta etapa se identificaron y negociaron los predios y, además, se desarrolló todo el proceso de selección de los candidatos que tenían que tener entre 18 y 35 años, ser miembros posiblemente de una familia vinculada al agro, tener experiencia en las labores de campo y vocación cafetera, además de un nivel educativo por lo menos básico y una buena reputación en sus respectiva comunidad.

La segunda etapa, "de desarrollo" tuvo una duración de 42 meses; en ella se gestionaron los recursos financiero y los créditos, primero a través de una aportación directa del Comité de Cafeteros y posteriormente a través de entidades bancarias y la mediación del Comité. En esta fase los jóvenes adquieren concretamente los terrenos en calidad de propietarios, con la posibilidad de cancelar el crédito durante un lapso total de 12 años, sin cuotas los primeros 5 . "Durante este tiempo se adelanta la instalación y seguimiento de los proyectos productivos, el desarrollo de un plan ambiental y la comercialización del café. Simultáneamente se promueve el fortalecimiento del tejido social y el fortalecimiento organizacionaln. ${ }^{9}$ 
Durante esta fase el apoyo tanto de los profesionales de agronomía como de los trabajadores sociales fue muy importante; los primeros, naturalmente, para todo el ámbito productivo, los segundos para el componente organizacional, de convivencia comunitaria y de trabajo en equipo. A cada joven se le asignaron 5 hectáreas pero las fincas podían estar habitadas y compartidas por varios jóvenes y sus respectivas familias; "Con el paso del tiempo el programa vinculó la modalidad de arrendamiento de fincas a diez años con la probabilidad de compra después de la finalización del contrato, conservando el mismo enfoque y proceso de adquisición de fincas, con la variante de que se trata de usufructuar al máximo la tierra por el espacio que dura el contrato, enfatizado en el trabajo en equipon. ${ }^{10}$

La tercera y última fase fue la de "Consolidación y autonomía" (1 año), durante la cual se evaluó el camino inicial recorrido por los grupos de jóvenes escogidos por el programa y se disminuyó progresivamente la presencia y el acompañamiento de las entidades que lo promovieron.

Según el investigador Luis Fernando Barón Porras, "las claves de esta experiencia están en una serie de asuntos interrelacionados, a saber: en el fortalecimiento de la autoestima y la identidad campesina y cafetera de los jóvenes; en el restablecimiento de la confianza vecinal y en el desarrollo y reorganización de espacios de trabajo y acción comunitaria; en el desarrollo de proyectos agrícolas que, además de contribuir a la seguridad alimentaria, son viables y sustentables; en la reactivación de circuitos económicos comunitarios y locales, y en el reconocimiento social y en el soporte brindado por la Federación Nacional de Cafeteros y su vinculo con las organizaciones cafeteras del departamento como Cencoa". ${ }^{11}$

Tabla 1: extrusión de las fincas. fuente Asojay. 2013

\begin{tabular}{|c|c|}
\hline \multicolumn{2}{|c|}{$\begin{array}{l}\text { Extensión de las fincas y número de productores } \\
\text { asociados a ASOJAV }\end{array}$} \\
\hline De 0 a 5 hectáreas & 13 asociados \\
\hline De 5 a 10 hectáreas & 34 asociados \\
\hline De 10 hectáreas en adelante & 3 asociados \\
\hline total & 50 asociados $(+2)^{*}$ \\
\hline
\end{tabular}

Sin embargo, el programa también conoció varias dificultades, en otras: a) en los primeros años, sobre todo a causa de la caída del precio internacional del café, la caficultura no estaba generando ingresos; por tanto los jóvenes se vieron obligados a trabajar, paralelamente, en otras fincas; b) la caída del precio internacional del café, además, obligó a una renegociación parcial de los plazos de pago de los créditos; c) la inseguridad de varias zonas por ciertos actos y amenazas de los grupos armados ha dificultado los desplazamiento de técnicos y funcionarios; d) los subsidios de vivienda no logran cubrir las necesidades de las familias involucradas; e) algunos jóvenes han abandonado el programa a causa del conflicto armado; f) "sentimiento generalizado de los campesinos de no sembrar cultivos de pan coger para evitar la intromisión de los grupos armados al margen de la ley en las fincas". ${ }^{12}$

492 
"En la actualidad el programa cuenta con 28 proyectos ya productivos", nos informa Franklin Castillo Sánchez, ${ }_{13}^{3}$ actual coordinador del programa. "Son experiencias grupales que se conforman a nivel de una vereda. ASOJAV, en este sentido, ya es el resultado de la asociación de varios grupos, del trabajo de varios líderes en los diferentes grupos que han comprendido la necesidad de articularse en un nivel mayor. Estos grupos varian en tamaño: hoy el más pequeño es de 3 familias y el más grande de 23".

Los grupos de café son 23 y abarcan una superficie de 652 hectáreas. Pero en los últimos años también se empezaron cinco proyectos ligados a la producción de caña panelera, por un total de 91 hectáreas. "Esto nos daría un total de 743 hectáreas de área productiva; sin embargo, ya entregamos 200 hectáreas más en las cuales aún no han empezado procesos productivos. En total son 165 familias, 147 en café y 18 en caña; 413 beneficiarios directos, en 15 municipios del Valle del Cauca». La experiencia con la caña se desarrolló a partir del año 2000 sobre todo en dos municipios, Sevilla y Ansermanuevo, donde por condiciones climáticas y por la roya muchas familias salieron de la caficultura, pero no por eso el Comité de Cafeteros dejó de apoyarles. "Hoy estas familias han conformado organizaciones con marcas propias y se han agrupado en Fedepanela (Federación Nacional de Productores de Panela, N.d.R.); han alcanzado buenos niveles de comercialización e incluso algo de exportación, pero más a nivel agroindustrial".

Hoy el programa ya no trabaja con recursos propios, sino con créditos bancarios; se ha ganado la confianza del sector financiero y ha conseguido créditos muy bajos para poder seguir acercando a los jóvenes y entregar nuevas tierras. El nivel de edad de los aspirantes ha bajado con relación al principio y ahora se encuentra en un promedio de 26 años. "El Valle del Cauca es pionero en esta experiencia; a raíz de ella, en 2010, la Federación quiso replicarla a nivel nacional, modificando un poco el modelo que nosotros estamos implementando y la verdad es que no tuvo el éxito que se esperaba".

Franklin subraya, además, que la experiencia del Valle ha ido evolucionando y adaptándose a las coyunturas: "hoy, viendo que la compra de tierras es un tema complejo y costoso, y que la cooperación internacional en Colombia es cada vez más limitada, nos hemos planteado que la experiencia de relevo generacional se puede plantear también de otra forma. Aquí nacen, por tanto, los modelos de arrendamiento y han funcionado excelentemente. La crisis actual de los precios está sacando del negocio especialmente a los caficultores medianos; nuestra idea es que esas áreas de caficultura no se pierdan, por tanto apoyamos a los jóvenes a que las tomen en arriendo. La compra de tierras ya no es el único modo que nos planteamos desde el programa para fomentar el relevo generacional".

Entre los asociados de ASOJAV hay una experiencia de este tipo, y algo particular porque desarrollada en una finca donde no había producción cafetera. Nos la contó Gonzalo Garcés, ${ }^{14}$ del municipio de Ovando, que hace 4 años es miembro de la asociación: "Al contrario de los otros asociados que todos son propietarios y están poco a poco pagando las cuotas del crédito, nosotros somos arrendatarios de una finca. Gracias a la intermediación del Comité Departamental de Cafeteros, estipulamos un contrato de 12 años con el propietario. Nos faltan 3 años, si al finalizar el contrato el propietario quisiera vender la finca, pues nosotros estamos dispuestos en comprarla si conseguimos apoyos y un crédito. Prácticamente arrancamos de cero, porque en la finca no había nada de café; empezamos en el 2004, entrando en el programa de jóvenes agricultores. Al principio éramos cinco compañeros, ahora quedamos tres. Tres familias que, además de compartir el trabajo en la finca, también 
compartimos la misma casa. Llevamos casi 10 años viviendo juntos, superando adversidades juntos, pero firmes en la idea de sacar adelante la producción cafetera. Tenemos 21 hectáreas en café y 17 de bosques, reserva forestal donde no se pueden llevar a cabo actividades agrícolas. Producimos más o menos $3.800 \operatorname{arrobas~}^{15}$ al año y dividimos los beneficios globales entre las tres familias. Cafenorte, en el municipio de Cartago, nos compra el café a 37.000 pesos (alrededor de 19 USD) la arroba".

\section{La vinculación con el comercio justo internacional}

Como adelantamos anteriormente, cuando los jóvenes del Valle respondieron a la convocatoria del programa Jóvenes Agricultores, la crisis internacional del café empezaba a agudizarse, además recrudecida por la desaceleración económica nacional de 1999. Entre los primeros años 60 y finales de los 80, el mercado internacional del café era estrictamente regulado por los Acuerdos Internacionales del Café. En este periodo, el precio fluctuaba entre un dólar y un dólar y medio la libra, a excepción de aquellos años en los cuales se produjeron fuertes heladas en Brasil; en general, era un sistema estable y los precios relativamente altos. Las crisis del café se debieron principalmente a la ruptura del último Acuerdo Internacional del Café en 1989 (que mantenía un precio mínimo de 1.20 dólares la libra) ${ }^{16} \mathrm{y}$ al aumento de la oferta mundial tras el ingreso de nuevos productores, especialmente Vietnam, obligados por los organismos internacionales a aumentar sus exportaciones para poder pagar la deuda, ${ }^{17} \mathrm{y}$ también a la modernización y la introducción de cultivos más intensivos en Brasil. Nuevas técnicas que, sin embargo, redujeron la calidad del café y degradaron los terrenos, hasta que las mismas transnacionales del sector, a pesar de las enormes ganancias durante los años de bajos precios, reconocieron los efectos negativos que suponía seguir perdiendo en términos de calidad.

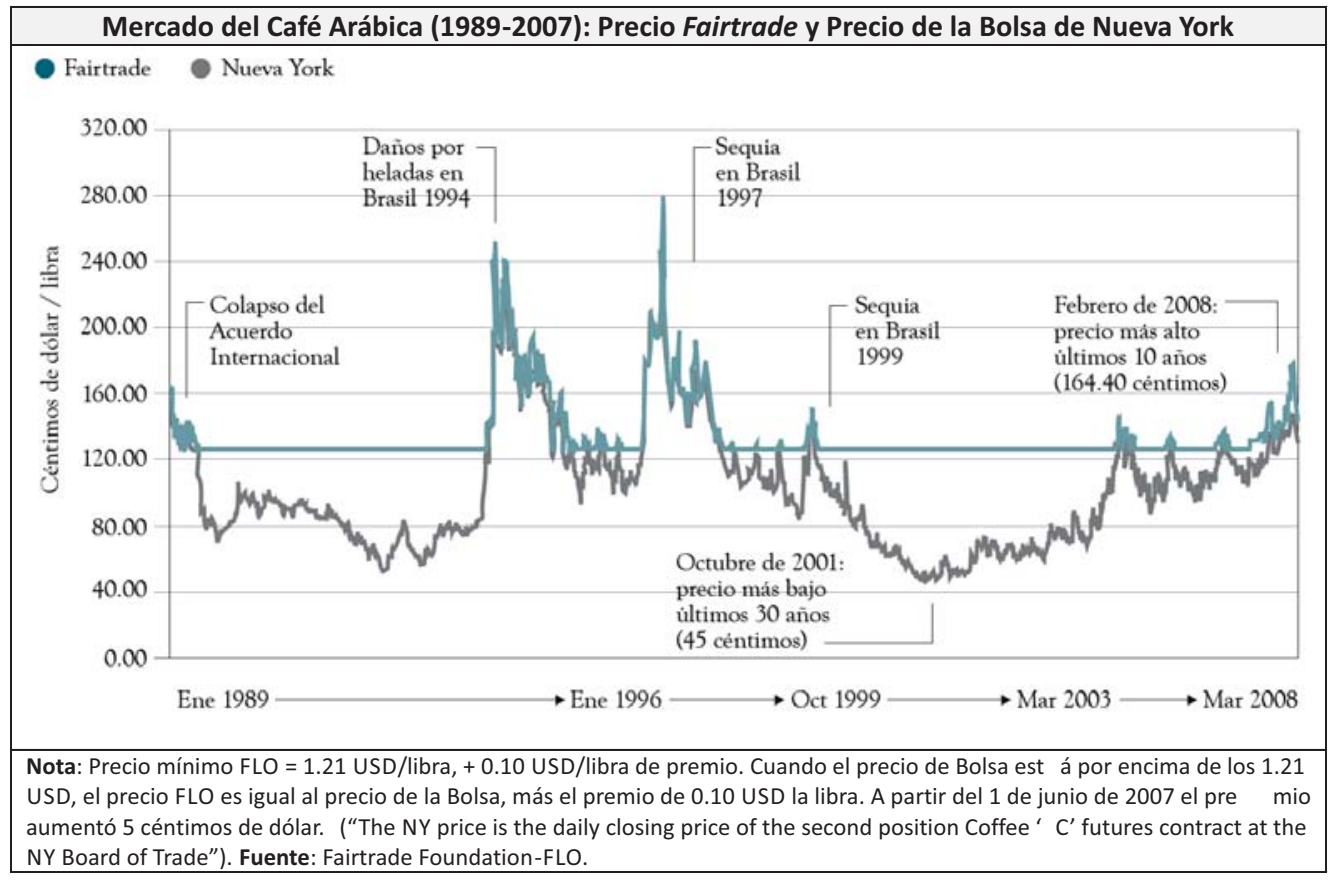


Desde 1989, el mercado del café ha estado prácticamente desregulado y son los grandes operadores comerciales a nivel mundial los que, en las bolsas de Nueva York (arábica) y Londres (robusta), fijan los precios del mercado internacional. Es justamente a finales de los años 80 que, gracias a la cooperación entre la ONG holandesa "Solidaridad" y la Unión de Comunidades Indígenas de la Región del Istmo "UCIRI" certificación de calidad de comercio justo. El lanzamiento oficial del Café Solidaridad con el sello Max Havelaar tuvo lugar el 15 de noviembre de 1988, en Holanda: el primer paquete de café tostado de la casa Neuteboom fue presentado al príncipe Claus.

A partir de ese momento, el movimiento mundial por un comercio justo mantiene un precio mínimo para el café (así como para otros productos) debajo del cual no se pueden llevar a cabo negociaciones comerciales "justas". Como podemos notar en la siguiente gráfica, ese precio mínimo permitió a los caficultores resistir las dos crisis más fuertes: la primera entre 1989 y 1993 y la segunda entre 1997-99 y 2004. En octubre de 2001, cuando el precio internacional del café arábica bajó hasta 45 céntimos de dólar la libra, los pequeños productores de comercio justo recibian, en promedio, 80 céntimos más respecto a los productores convencionales.

Fue por esas razone que "los jóvenes que fuimos escogidos por el comité entendimos que teniamos que encontrar alternativas viables que pudieran garantizar la comercialización del producto con un precio diferenciado", comenta Jorge Salinas. Ese canal de comercialización alternativo se reconoció en el comercio justo, un nicho de mercado ya en aquel entonces en pleno crecimiento. Para la Asociación la vinculación con el comercio justo y el proceso de certificación fueron relativamente rápidos. Como recuerda Jorge, "ASOJAV se fundó en el 2000 con 38 productores, y ya en el año 2001 obtuvimos la inscripción en la Fairtrade Labelling Organizations International. A partir del año 2003, recibimos la certificación Fairtrade, un año después de su creación a nivel internacional. Fue sobre todo gracias al gran interés demostrado en aquel entonces por la empresa tostadora estadounidense Santa Cruz Coffee Roasting que el proceso pudo desarrollarse tan rápidamente. Con la ciudad de Santa Cruz en California, además, pudimos desarrollar durante varios años un proyecto muy interesante. Nosotros exportábamos nuestro café y una organización de allá lo comercializaba a través de jóvenes que se intentaba sacar de las bandillas locales. Fue muy interesante esa relación. Hoy ya somos 52, pero dos de ellos en este momento no están produciendo. Lo que nos ayudó mucho fue poder utilizar también parte del premio social de comercio justo para el pago de las tierras adquiridas por los jóvenes. En la actualidad un $25 \%$ de nosotros ya pudimos cancelar la totalidad del crédito para la compra del terreno".

Para los jóvenes de Asojav que pude entrevistar, el comercio justo ha sido sobre todo una gran oportunidad: "la oportunidad de recibir un poco más por nuestro trabajo, pero también ha sido el empuje que nos ayudó y animó a mejorar la calidad de nuestro producto, a cumplir con requisitos internacionales y prácticas locales de sostenibilidad", comenta Juan Carlos Sánchez (del grupo Los Naranjos del municipio de Argelia, en la zona Norte del Valle, y actual vicepresidente de Asojav) ${ }^{19}$. Además, Juan Carlos subraya como, en esta coyuntura tan dificil para la caficultura, el apoyo a la asociatividad que proviene del comercio justo ha sido fundamental.

"Además, a través del comercio justo uno se siente partícipe de algo no solamente local sino también nacional, porque en Colombia hay muchas organizaciones como la nuestra, y de algo global", son las palabras de Wilton Reina ${ }^{20}$, productor de la vereda El Bosque, municipio Yotoco, 
que desde hace 9 años es miembro de la asociación y hace tres se desempeña como tesorero de la junta directiva. "De hecho, el beneficio más grande, que siento a través de las relaciones de comercio justo que tenemos a través de ASOJAV, es todo el componente social. No tanto lo económico, que naturalmente alivia la carga y cuenta mucho, sino la posibilidad de participar en una asociación, de relacionarme con otros productores y con la sociedad en su conjunto. Aprender del medio, de las capacitaciones, interactuar con muchas personas de distintos lugares, de Colombia y del mundo".

"El comercio justo es un apoyo para el pequeño productor, que lo está necesitando mucho", afirma Jerson González $z^{21}$, hace 10 años miembro de ASOJAV. "Ojalá hubiera más comercio justo para que apoyen más al pequeño, porque el grande no lo necesita. El grande productor no vive de eso, la caficultura es solo una parte de su negocio; por el contrario, el pequeño sí vive de la caficultura. Para mí el gran beneficio del comercio justo es que está involucrando a toda la familia y al trabajador que está con nosotros en la finca".

El Premio Social de Comercio Justo y la diversificación productiva

El premio o prima Fairtrade es, prácticamente, un sobreprecio que se aplica al precio mínimo; sin embargo, su valor debe ser contabilizado de manera diferente y utilizado para inversiones sociales entre los asociados o en las comunidades, o para mejorar la productividad y la calidad de los cultivos. Según la definición de la misma organización Fairtrade, el premio "[...] ayuda a los productores a mejorar su calidad de vida. Es una suma de dinero adicional y los productores deciden democráticamente cómo usarla. Generalmente la invierten en proyectos educativos, sanitarios, mejoras agrícolas o instalaciones de procesamiento para incrementar sus ingresos". ${ }^{22}$

Tabla 2

\begin{tabular}{|c|c|c|}
\hline \multicolumn{3}{|c|}{ Producción y exportación de café (2004-2013) } \\
\hline Año & $\begin{array}{c}\text { Producción en } \\
\text { Kilogramos café } \\
\text { pergamino seco }\end{array}$ & $\begin{array}{c}\text { Exportación en sacos de } \\
70 \mathrm{Kg} \text { (excelso o verde) y } \\
\text { en Kilogramos (verde) }\end{array}$ \\
\hline 2004 & 394,133 & 1,120 sacos \\
\hline 2005 & 275,867 & 142,849 Kgs \\
\hline 2006 & 301,334 & 2,345 sacos \\
\hline 2007 & 381,884 & 160,572 Kgs \\
\hline 2008 & 317,969 & 19.188 Kgs \\
\hline 2009 & 281,849 & 450 sacos \\
\hline 2010 & 243,775 & 285 sacos \\
\hline 2011 & 204,256 & no hubo exportación \\
\hline 2012 & 210,650 & 125 sacos \\
\hline 2013 & 203,337 & 500 sacos $+10,060$ Kgs \\
\hline Fuente: Asojav, noviembre de 2013 \\
\hline
\end{tabular}


A pesar de que Asojav, hasta el momento, logre vender solo un 10\% de la producción total en los circuitos del comercio justo ${ }^{23}$, las aportaciones de estos canales solidarios se materializan tanto a través premio social como de la misma venta a un precio diferenciado. Entre 2004 y 2013, por ejemplo, Asojav pudo entregar casi mil paquetes de útiles escolares a los niños de las familias de los asociados, y varios subsidios educativos por un valor total de 6 millones de pesos. Ha implementado un programa de mejoramiento de la calidad del café a través de la implementación de Buenas Prácticas de Manejo y "el uso de equipos para el beneficio, que garantizan la calidad sanitaria, sensorial, la inocuidad y trazabilidad", subraya Jorge.

Las bases del premio social y los beneficios de las ventas a través de los circuitos del comercio justo, además, le permitieron a Asojav crear un Fondo de crédito para el Desarrollo Integral (Fodi), especialmente dirigidos a los productores y productoras que, por los limitados ingresos, por las escasas garantías que pueden ofrecer o por la reducida cuantía del crédito, no pueden acceder fácilmente a los créditos bancarios.

La relación con el comercio justo ayudó a estimular la conformación de un Comité Femenino al interior de la Asociación; este comité no solamente agrupa a las productoras (que de momento son solamente cuatro) sino que también a las esposas y algunas hijas de los asociados. Su objetivo es orientar también a las mujeres hacia la participación en la producción, comercialización del producto y la administración de Asojav. La equidad de género y el empoderamiento de las mujeres es uno de los pilares fundamentales dentro de los principios básicos del comercio justo. Otro pilar es la gestión ambiental, esta también relacionada estrictamente con la sostenibilidad intergeneracional. "Hoy en día nuestra asociación cubre todo los requerimiento del comercio justo", subraya Jorge, "y se ha venido trabajando mucho en la conservación del medio ambiente. Estamos tratando de volver a tener los cafetales con sombríos y por eso vemos que la fauna vuelve otra vez a nuestros cafetales".

Este cuidado, que de por sí les permite a los productores de Asojav mantener altos los estándares de calidad del café, se combina, además, con una clara tendencia a la diversificación productiva dentro de las fincas: "nosotros realizamos un proyecto de diversificación en las fincas de los asociados. Fue un proceso gradual, arrancamos en 2003 y lo finalizamos en 2007, pero tuvo éxito. Sembramos frutales, sobre todo cítricos, mantuvimos los platanales y entregamos insumos y semillas para las huertas caseras. Algunos asociados tienen gallinas, pollos, cerdos y en general todos los asociados comercializan plátanos y bananos en los mercados locales". Las huertas caseras lograron disminuir la dependencia de los productores de la compra externa de otros productos como hortalizas y legumbres. Para el corto plazo, la asociación está trabajando para mejorar aún más la calidad de plátanos y bananos y articular un nuevo canal de comercialización nacional.

Últimamente, el precio del café está bajando paulatinamente, mientras que el costo de los fertilizantes se mantiene constante o aumenta. Estos factores, junto con las consecuencias negativas del cambio climático, están provocando, según nos relata Juan Carlos, la disminución de la productividad de las fincas. Entre los peores efectos del cambio climático Jorge subraya "los dos extremos. Cuando tenemos oleadas invernales, mucho invierno, baja la floración de las plantas y, por tanto, baja la producción. Cuando hay mucho calor, por lo contrario, se quema el fruto. Los cambios bruscos y el desorden climático nos están afectando mucho; en la actualidad, yo por ejemplo, estoy produciendo entre 20 y 30 arrobas por hectárea, pero podría ser más". 
"Huracanes y granizadas son los eventos meteorológicos que más nos están afectando en los últimos tiempos; antes no era así", relata Jerson, cuya finca se encuentra en el corregimiento de Venecia (municipio de Trujillo). "Donde queda mi finca, por ejemplo, se están desarrollando vientos muy fuertes que hasta afectan a las casas y las pocas infraestructuras que tenemos. Lo que queremos hacer es sembrar filas de árboles cortavientos en el cañón, para frenar la fuerza del viento, pero aún no hemos podido conseguir los árboles ya bastante crecidos".

Al momento de la entrevista, la Cooperativa de Caficultores del Norte del Valle (recién certificada también por Fairtrade International) le estaba comprando, a Don Juan, una arroba de café (ya lavado y secado) por 38.000 pesos (20 USD): "lo que nos permite este precio es simplemente cubrir los gastos, ya no alcanza para las pequeñas reinversiones que siempre necesitan las fincas, aunque sea solo para abonar y aplicar fertilizantes. Lo que nos toca es alternar con otras producciones, hasta venta de pequeños animales de corral o cerdos. En el caso de Argelia hemos logrado conectarnos con una asociación de productores de plátanos que vende a empresas freidoras nacionales; de este modo podemos diversificar ingresos. Para mí ya se ha convertido casi en un $50 \%$ de los ingresos totales de los productos de la finca. De hecho, la primera cuota que voy a pagar por el terreno se cubrirá con los ingresos del plátano y no del café". Parece extraño, pero es la realidad de varios productores de café en esta coyuntura; sobre todo para los que, como Juan Carlos, hace solo pocos años han ingresado al programa de jóvenes agricultores. "Aunque el café seguirá siendo nuestro primer producto, sobre todo por la geografia de los territorios en los cuales se encuentran nuestras fincas, el desafio actual, a mi juicio, es seguir buscando alternativas. Lograr manejar otras fuentes de ingresos sería fundamental para nosotros, más aún si los niveles del café en los mercados internacionales siguen tan bajos", afirma Juan Carlos.

"En este momento la Cooperativa Caficentro me está comprando el café a 40.000 pesos (alrededor de 21 USD) la arroba", afirma Jerson. "Gracias al apoyo que tuvimos por parte del programa las fincas tienen buena producción de café variedad castillo, que Cenicafé (Centro Nacional de Investigaciones de Café, N.d.R.) introdujo en el país para resistir a la roya. Pero ahora la productividad está bajando y los gastos aumentando. Yo logro sustentarme con la producción de café, el problema es que ya no logro pagar las deudas; antes cuanto el negocio iba bien, muchos se endeudaban porque sabian que finalmente podia pagar las deudas, pero ahora el panorama ha cambiado".

Asojav y la apuesta por los jóvenes.

Empezar a través del programa "Jóvenes Agricultores" marcó profundamente toda la política de la asociación hacia los jóvenes de las comunidades y los hijos de los productores. "De hecho", comenta Jorge, "las aportaciones del premio que recibimos por parte de "Progreso Network" se destinarán a la siembra de nuevos cafetales para los hijos de aquellos asociados que en la actualidad, después de 13 años desde nuestra fundación, ya tienen alrededor de 50 años. De este modo queremos incentivar a esos adolescentes a que aprendan a cultivar y a amar el campo, para que sean los "caficultores del futuro", y a los padres que acompañen este proceso vivencial, formativo y poco a poco organizativo y empresarial. Si empezamos cuando los hijos son pequeños, al momento de alcanzar la mayor edad ya estarán en grado de trabajar y cuidar la finca. Ello nos garantiza el relevo generacional y la permanencia en el campo, dos problemas fundamentales para muchas familias campesinas $u$ organizaciones de productores". Hoy el promedio de edad de los jóvenes de la asociación es de 38 años y se está 
trabajando para que otros jóvenes del departamento se asocien y empiecen a comercializar de manera conjunta a través de Asojav, respetando los criterios sociales y ambientales del comercio justo; más aún en la actual coyuntura económica que está nuevamente golpeando a toda la caficultura, también aquí en Colombia.

Tabla 3

\begin{tabular}{|c|c|}
\hline \multicolumn{2}{|c|}{ Edades de los productores asociados } \\
\hline $29-35$ años & 17 asociados \\
\hline $36-40$ años & 15 asociados \\
\hline $41-45$ años & 10 asociados \\
\hline $46-50$ años & 5 asociados \\
\hline 51-55 años & 3 asociados \\
\hline \multicolumn{2}{|c|}{ Fuente: Asojav, noviembre de 2013} \\
\hline
\end{tabular}

"Nuestros padres siempre nos enseñaron que había que esforzarnos, que había que trabajar y que teníamos que dejar una herencia a nuestros hijos también", afirma Juan Carlos Sánchez en un video promocional desarrollado por Asojav. "No solamente trabajar para un beneficio propio, sino que dejarles algo a nuestros hijos. En Asojav somos partidarios del relevo generacional así como nuestros padres nos dejaron esa herencia y esa gran oportunidad hoy en dia de trabajar el campo, de lucha por esta empresa, de prosperar. [...] Que nuestros hijos se preparen un día no para dejar el campo e irse a la ciudad sino a ser empresarios del campo y sacar esto adelante. Porque en Asojav somos el presente y el futuro de la agricultura ${ }^{24}$. Los hijos de Juan Carlos tienen solo 10 y 11 años: "están en una edad que el campo y la agricultura les gusta; nos acompañan mucho en las actividades y nosotros les mostramos los labores de la finca desde el punto de vista educativo, del aprendizaje y del disfrute". Para Juan Carlos es importante darles el ejemplo y que ellos se sientan partícipes de un modo de vida: "todavía no están en la edad de pensar si quieran quedarse o no en la caficultura, pero mi esposa y yo intentamos mantener alto el interés por un ambiente en el cual se han criado".

"Gracias a ASOJAV nos dimos cuenta de la realidad del relevo generacional y de la importancia de mantener nuestros hijos ligados a las parcelas y a la caficultura", relata Wilton. "Pero tenemos que pensar en cómo hacer atractiva esta alternativa de vida para los jóvenes que, más bien, sienten el atractivo de otros espacios y otras actividades. Mi hija tiene 16 años, digamos que las labores agrícolas en sí no la atraen mucho, pero yo he logrado convencerla de que, aunque no quiera trabajar en la finca, sí podría quedarse, en un futuro, al frente de ella, administrándola. Y así hoy está estudiando en un colegio técnico agropecuarioforestal».

Esta apuesta por el campo y la juventud también en la relación entre Asojav y las comunidades y las instituciones locales: "Nuestro enfoque" sigue Jorge, "se basa en el fortalecimiento de nuevos liderazgos comunitarios. Muchos de los asociados son referentes en sus respectivas comunidades y ASOJAV es cada vez más reconocida por las comunidades; tenemos miembros en los comités locales de cafeteros, en las juntas de acción comunal en las 
veredas, y hasta hay un asociado que es concejal de uno de los 14 municipios donde están presentes nuestros asociados, sobre el total de 42 municipios del departamento".

Los integrantes de Asojav entienden que hay que seguir fortaleciendo las relaciones a nivel local y con las comunidades del Valle. Por esta razón, nos cuenta Jorge, los asociados han decidido emprender un nuevo camino: el de la comercialización local del producto. Si hasta ahora la gran parte de la producción se destina a la exportación, "ahora estamos iniciando un proyecto para comercializar masivamente el café de los jóvenes en las comunidades, empezando por las mismas veredas donde se encuentran nuestros asociados. Aún estamos en el proceso de legalización de la marca para los registros ante el Instituto Nacional de Vigilancia de Medicamentos y Alimentos (Invima), y tenemos que encontrar los recursos suficientes para poder montar nuestra propia planta de procesamiento. La inversión es alta y tenemos que buscar apoyo externo", afirma Jorge. "¿Qué más pudiera enorgullecernos que vender nuestro productos en nuestras veredas, en nuestras comunidades, entre los vecinos y la gente de la cabecera municipal?", nos pregunta Wilton. "Es por eso que apoyamos este tipo de proceso. En lugar de seguir comprando y consumiendo café barato y de baja calidad pues tenemos que crear otro tipo de cultura del consumo del café».

"En la asociación también hay varias cosas que tenemos que mejorar", nos cuenta Nelson. "Para mí, por ejemplo, algo que nos está perjudicando como asociación es que varios socios están vendiendo el café mojado. Entonces tenemos que mejorar el apoyo a los productores para que todos entreguen el café ya bien secado y se pueda asî responder, más ágilmente, a las necesidades de la demanda de café con cierto grado de beneficio. Naturalmente, muchos lo hacen por necesidad, porque no pueden esperar la semana o los diez días más que necesita el proceso de secado; y, por tanto, venden directamente el café después del lavado". Según Gonzalo, otra de las tareas en las cuales la asociación tiene que mejorar es el acercamiento a otros productores no organizando, para que también puedan beneficiarse del asociativismo $\mathrm{y}$, al mismo tiempo, ayuden ASOJAV a crecer.

\section{Conclusiones.}

La realidad del comercio justo en Colombia es casi desconocida.

No existe una sistematización de las informaciones disponibles, de las aportaciones cotidianas que las organizaciones de pequeños productores hacen al desarrollo rural gracias a las relaciones solidarias con el comercio justo.

Tampoco existe, todavía, una estrategia concreta de las instituciones públicas para considerar este tipo de "asociación mundial" y su enfoque multidimensional de desarrollo, como una pieza fundamental para la reescritura de las relaciones económicas, sociales y politicas en el campo. Sin embargo, el movimiento del comercio justo sabe que tiene un enorme potencial en Colombia y que las organizaciones de productores también necesitan construir nuevos canales solidarios tanto internacionales como nacionales.

Más aún, en esta coyuntura histórica, cuando las conversaciones de Paz en La Habana entre el Gobierno Colombiano y la insurgencia armada de las FARC-EP, han vuelto a poner el acento en la cuestión agraria (problema de fondo y estructural detrás de las largas décadas del conflicto armado), y cuando el paro nacional agrario subrayó como, a través de la movilización campesina y la solidaridad ciudad-campo, sea posible visualizar colectivamente un futuro distinto.

500

AGO.USB Medellín-Colombia $\quad$ V. $13 \quad N^{\circ} 2$ PP. 279- 539 Julio-Diciembre 2013 ISSN: 1657-8031 
En este momento histórico, como subrayó don Jorge durante la entrevista, no hay duda que, en un hipotético escenario de post-conflicto, Asojav va a ser un referente fundamental para el trabajo con y desde los jóvenes, para un desarrollo rural y comunitario sostenible intergeneracionalmente, basado en la organización y en los principios solidarios del comercio justo.

Al abrirse las puertas de la asociación, comenta Juan Carlos:

"Encontramos ese ambiente social que uno, solito en su vereda, nunca podría conocer. No hablo solamente de capacitaciones e intercambios que, por cierto, son fundamentales para mejorar nuestras actividades productivas, o de los beneficios que podríamos recibir de la relación de comercio justo a través de Asojav, sino hablo sobre todo del poder compartir con otros asociados y profesionales y tejer otro tipo de relaciones humanas basadas en la solidaridad y la confianzan. 


\section{Referencias bibliográficas}

ASOJAV (s.f.): Video “ASOJAV. (Asociación de Jóvenes Agricultores del Valle del Cauca)”.

Barón Porras, Luis Fernando (s.f.): "Estudios de caso sobre buenas prácticas para superar el conflicto en el Valle del Cauca"; informe resultado del trabajo colectivo desarrollado por el Centro de investigación de la Facultad de Derecho y Ciencias Sociales de la Universidad ICESI (Cali, Colombia) con el apoyo del Banco de Buenas Prácticas para Superar el Conflicto. Disponible en: http://www.icesi.edu.co/revistas/index.php/revista_cs/article/view/433/1409.

Bohórquez Caldera, Luis Alfredo. (2013). Colonización de la naturaleza: una aproximación desde el extractivismo en colombia. En Revista El Agora USB, ISSN 1657-8031, Vol 13 n 1. Pag $473-495$.

Fridell, Gavin. (2007). Fair Trade Coffee. The prospects and pitfalls of market-driven social justice, University of Toronto Press, Canadá.

Insuasty Rodriguez, Alfonso. (2013). La Nueva era BIO: Consideraciones Éticas y Filosofias. Una reflexión para el Porvenir. Ed. Kavilando. Medellín - Colombia.

Jaffee, Daniel. (2007). Brewing Justice. Fair Trade Coffee, Sustainability and Survival, University of California Press, California-Estados Unidos y Londres-Reino Unido.

Luis Fernando Barón Porras. (s.f.). "Estudios de caso sobre buenas prácticas para superar el conflicto en el Valle del Cauca"; informe resultado del trabajo colectivo desarrollado por el Centro de investigación de la Facultad de Derecho y Ciencias Sociales de la Universidad ICESI (Cali, Colombia) con el apoyo del Banco de Buenas Prácticas para Superar el Conflicto. Disponible en: http://www.icesi.edu.co/revistas/index.php/revista_cs/article/view/433/1409.

Oxfam International. (2002). Pobreza en tu taza. La verdad sobre el negocio del café, Intermón Oxfam, Barcelona.

\section{Notas}

${ }^{2}$ Video “ASOJAV (Asociación de Jóvenes Agricultores del Valle del Cauca)”.

${ }^{3}$ Progreso Network nació en 2005 en Holanda como una comunidad y plataforma de aprendizaje para el intercambio de experiencias, capacidades, conocimientos e informaciones entre organizaciones de pequeños productores de café. A través de la

502

AGO.USB Medellín-Colombia V. $13 \quad N^{\circ} 2$ PP. 279- 539 Julio-Diciembre 2013 ISSN: 1657-8031 
comunidad, los interlocutores (productores, profesionales, importadores, organizaciones, etc.) pueden compartir experiencias y conocimiento y asi tejer nuevas relaciones o fortalecer las existentes. Nació como un proceso de capacitaciones e intercambios presenciales pero a partir de 2009 desarrolla sus actividades prevalentemente on-line. En la actualidad son miembros de la comunidad alrededor de 1600 personas que representan a más de 200 mil productores en 24 países del mundo. Desde mayo de 2013, la CLAC se encarga de su gestión y articulación. Véase: <http://progresonetwork.ning.com/page/sobre-nosotros>

${ }^{4}$ Entrevista a Jorge Salinas, Bogotá D.C., 19 de noviembre de 2013.

${ }^{5}$ Véase: <http://www.cencoa.com.co/>.

${ }^{6}$ Véase: <http://www.vanguardia.com/economia/nacional/150223-el-campo-se-estaquedando-solo-y-viejo>.

${ }^{7}$ Véase:

<http://www.saliendodelcallejon.pnud.org.co/buenas_practicas.shtml?x=6986>.

${ }^{8}$ Íbidem.

${ }^{9}$ Véase:

<http://www.saliendodelcallejon.pnud.org.co/buenas_practicas.shtml?x=6986>.

${ }^{10}$ Ibídem.

${ }^{11}$ Luis Fernando Barón Porras (s.f.): "Estudios de caso sobre buenas prácticas para superar el conflicto en el Valle del Cauca"; informe resultado del trabajo colectivo desarrollado por el Centro de investigación de la Facultad de Derecho y Ciencias Sociales de la Universidad ICESI (Cali, Colombia) con el apoyo del Banco de Buenas Prácticas para Superar el Conflicto. Disponible en:

<http://www.icesi.edu.co/revistas/index.php/revista_cs/article/view/433/1409>.

${ }^{12}$ Véase:

<http://www.saliendodelcallejon.pnud.org.co/buenas_practicas.shtml?x=6986>.

${ }^{13}$ Entrevista a Franklin Castillo Sánchez, Tuluá (Valle del Cauca), 16 de diciembre de 2013.

${ }^{14}$ Entrevista a Gonzalo Garcés, Tuluá (Valle del Cauca), 16 de diciembre de 2013.

${ }^{15}$ Una arroba equivale a 25 libras o 11,5 kilogramos.

${ }^{16} \mathrm{El}$ Gobierno de Ronald Reagan prácticamente saboteó la renovación, oponiéndose a la misma, bajo las presiones de dos gigantes del café como Procter \& Gamble y Sara Lee; véase Jaffee, D. (2007): Brewing Justice. Fair Trade Coffee, Sustainability and Survival, University of California Press, California-USA y Londres-UK, pp. 42-43; y Oxfam International (2002): Pobreza en tu taza. La verdad sobre el negocio del café, Intermón Oxfam, Barcelona, p. 17. 
${ }^{17}$ "The neoliberal policy prescriptions of international financial institutions have played a key role in the collapse of the ICA [International Coffee Agreement], which has led to an extreme downward spiral in coffee prices. This situation has been made worse by the debt crisis and the neoliberal policies of the World Bank and IMF, who have used their leverage over indebted poor countries to promote the expansion of commodity exports", en Fridell, G. (2007): Fair Trade Coffee. The prospects and pitfalls of market-driven social justice, University of Toronto Press, Canadá, p. 89.

${ }^{18}$ "Es la organización cafetalera más antigua del estado de Oaxaca, se fundó en 1982, con 17 comunidades cafetaleras interesadas en mejorar las condiciones de producción y venta del café y el bienestar campesino, con ayuda de la diócesis de Tehuantepec y de ONGs europeas. Actualmente agrupa a 2,600 miembros de 56 comunidades zapotecas y mixtecos del centro y norte del Istmo, chontales del sur, Chatinos de la Costa y Mixes de la parte media y alta". Véase: <http://www.uciri.com>

${ }^{19}$ Entrevista a Juan Carlos Sánchez, Tuluá (Valle del Cauca), 16 de diciembre de 2013.

${ }^{20}$ Entrevista a Wilton Reína, Tuluá (Valle del Cauca), 16 de diciembre de 2013.

${ }^{21}$ Entrevista a Jerson González, Tuluá (Valle del Cauca), 1 | 6 de diciembre de 2013.

${ }^{22}$ Definición facilitada por FLO disponible en:

$<$ http://www.fairtrade.net/benefits_of_fairtrade.html?\&L=1>.

${ }^{23}$ Según las estimaciones de Jorge Salinas, las organizaciones de caficultores de comercio justo de Colombia actualmente solo logran colocar entre un 10 y un $15 \%$ de sus producciones a través de los canales solidarios.

${ }^{24}$ Video “ASOJAV (Asociación de Jóvenes Agricultores del Valle del Cauca)”. 